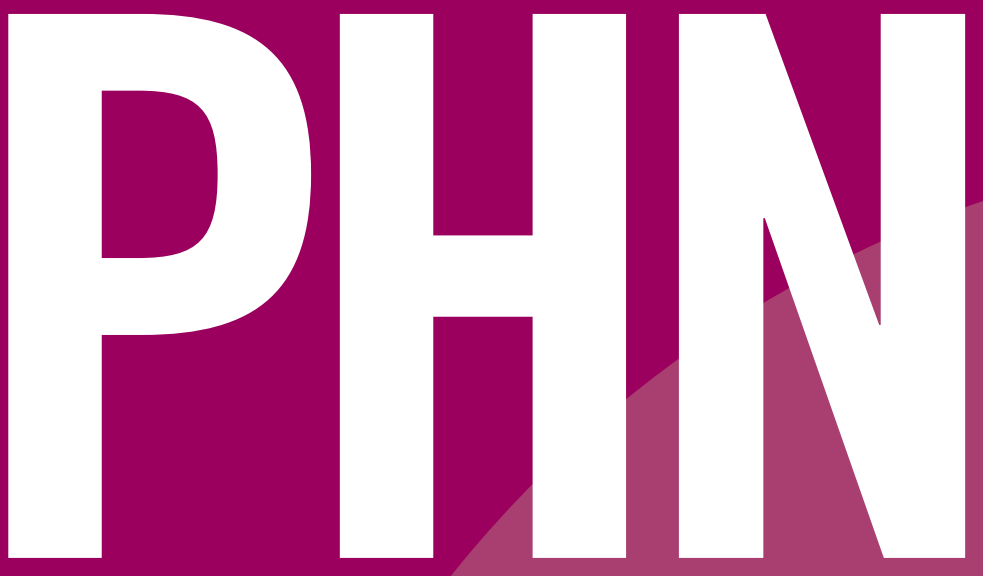

\title{
PUBLIE HEALTH
}

NUTRITION

\section{Volume 15}

Number 6

June 2012

\section{Available online at}

www.journals.cambridge.org/phn

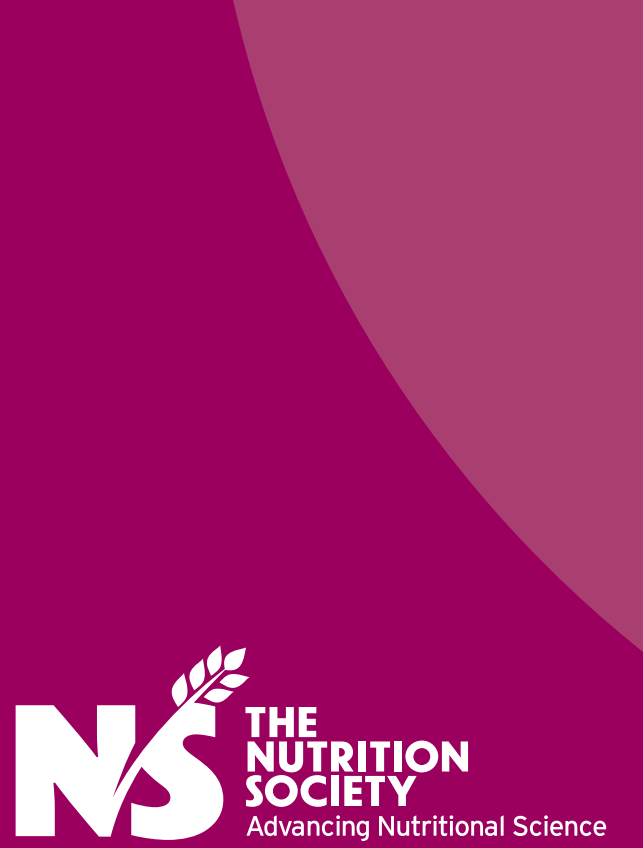




\title{
Public Health Nutrition
}

\author{
Volume 15, 2012 ISSN: 1368-9800
}

Twelve issues per year

Aims and Scope

\begin{abstract}
Public Health Nutrition provides an international forum for the publication and dissemination of research and scholarship in the form of peer-reviewed original papers and reviews, and for discussion in the form of editorials, commentaries, and correspondence, with a specific focus on nutrition-related public health.

The scope of Public Health Nutrition includes food systems and supplies, patterns of diet, foods and drinks, nutrients, body composition, physical activity, and associated factors, and their effects on disease, health and well-being, and the whole living and physical world. We welcome papers that:

- Address nutritional status assessment, monitoring, and surveillance

- Identify and analyse social, cultural, biological, environmental, economic and political determinants of nutrition-related public health

- Build intelligence about the development and evaluation of environmental and settings-based interventions focused on the availability of foods including interventions in the out of home eating environment.
\end{abstract}

\section{Editor-in-Chief}

Professor Agneta Yngve

Department of Health, Nutrition and

Management, Faculty of Health Sciences,

Oslo and Akershus University College of

Applied Sciences, Postbox 4, St. Olavsplass,

NO 0130 Oslo, Norway

Email:phn@nutsoc.org.uk

Deputy Editors

Research Professor Marilyn Tseng

California Polytechnic State University

San Luis Obispo, USA

Dr Irja Haapala

University of Eastern Finland, Finland

Dr Allison Hodge

University of Melbourne, Australia

Advisory Board

Professor Barbara Ainsworth, Arizona State University, USA

Professor Janet Cade, University of Leeds, UK

Professor Emeritus Leif Hambraeus, Karolinska Institutet, Sweden

Professor Carlos A Monteiro, University of São Paulo, Brazil

Professor Kerin O'Dea, University of South Australia, Australia

Professor Heizo Tanaka, Kanagawa Institute of Technology, Japan

Professor Hester Vorster, North-West University, South Africa

Statistical Editor

Dr Grietje Holtrop, University of Aberdeen, UK

First Editors

Dr Faruk Ahmed, Kuwait University, Kuwait

Professor Kylie Ball, Deakin University, Australia

Professor Thomas Baranowski, Baylor College of Medicine, USA

Dr Mary Barker,

University of Southampton, UK

Dr Maree Brinkman, University of Melbourne, Australia
- Describe, discuss, debate and influence food and nutrition policy

- Focus on improving food and nutrition-related public health, particularly in populations that are most vulnerable and at risk.

- Discuss and build capacity for effective public health nutrition action, including workforce development and educational issues

- Develop and test innovative and emerging models, methods and approaches to public health nutrition practice and research.

We prefer papers that are innovative and contribute new knowledge to the literature. Papers should be succinct (ie, usually well under 5,000 words including references). Short communications are welcome. We publish research, scholarship, and discussions that take a population and preventive approach. In addition to original contributions, ideas and suggestions for topics for debate are also welcome. We publish special issues.

Public Health Nutrition is available on the Internet at: journals.cambridge.org/phn

\section{International Editorial Board}

Dr Victoria Burley, University of Leeds, UK Associate Professor Marly A. Cardoso, University of Sao Paulo, Brazil

Dr Junshi Chen, Institute of Nutrition and Food Hygiene, China

Professor David Crawford, Deakin University, Australia

Dr Ilse de Bourdeaudhuij, Ghent University, Belgium

Associate Professor Eva-Charlotte Ekström, Uppsala University, Sweden

Associate Professor Lia Fernald University of California, Berkeley, USA

Dr Oliver Gillie, Health Research Forum, UK

Associate Professor Ingibjorg Gunnarsdottir, University of Iceland, Iceland

Dr Cécile Knai, London School of Hygiene \& Tropical Medicine, University of London, UK

Dr Carl Lachat, Gent University, Belgium

Dr Pagona Lagiou, University of Athens Medical School, Greece

Professor Christel Lamberg-Allardt University of Helsinki, Finland

Associate Professor Mark Lawrence, Deakin University, Australia

Professor Lauren Lissner, University of Gothenburg, Sweden

Associate Professor Geoffrey Marks University of Queensland, Australia

Ms Kaye Mehta, Flinders University, Australia

Professor Bent Egberg Mikkelsen, Aalborg University, Denmark

Associate Professor Annhild Mosdøl, Oslo and Akershus University College of Applied Sciences, Norway

Assistant Professor Aydin Nazmi, California Polytechnic State University, USA

Dr Punam Ohri-Vachaspati, Arizona State University, USA

Dr Carmen Perez-Rodrigo, Unidad de Nutrición Comunitaria, Spain

Dr Kelley Pettee Gabriel, University of Texas Health Science Center, USA
Dr Shobha Rao, Agharkar Research Institute, India

Dr Aiguo Ren, Peking University, China

Dr David Roberts, Independent Consultant, Australia Associate Professor Eva Roos, Folkhälsan Research Institute, Finland

Professor Jaap Seidell, VU University, The Netherlands

Professor Lluis Serra-Majem, University of Las Palmas de Gran Canaria, Spain

Professor Sangita Sharma, University of Alberta, Canada

Professor Rosely Sichieri, State University of Rio de Janeiro, Brazil

Dr Nelia Steyn, Human Sciences Research Council, RSA

Professor Birgitta Strandvik Karolinska Institutet, Sweden

Professor Janice Thompson, University of Bristol, UK

Professor Inga Thorsdottir, University of Iceland, Iceland

Dr Anna Timperio, Deakin University, Australia

Dr Katherine Tucker, Jean Mayer USDA HNRCA at Tufts University, USA

Dr Megumi Utsugi, National Institute of Health and Nutrition, Japan

Dr Joop van Raaij, National Institute for Public Health and the Environment (RIVM), Netherlands

Professor Maria Daniel Vaz de Almeida, Porto University, Portugal

Dr Eduardo Villamor, University of Michigan School of Public Health, USA

Dr Karen Z Walker, Monash University, Australia

Professor Susan Walker, University of the West Indies, Jamaica

Dr Christopher Wharton, Arizona State University, USA

Associate Professor Elisabet Wirfält, Lund University, Sweden

\section{The Nutrition Society}

The society has as its objective the advancement of the scientific study of nutrition and its application to the maintenance of human and animal health.

Particulars of The Nutrition Society and application forms for membership are available from the Honorary Secretary,

The Nutrition Society, 10 Cambridge Court, 210 Shepherds Bush Road, London W6 7NJ, UK.

Telephone +44 (0)207602 0228, Fax +44 (0)207602 1756

The Nutrition Society home page is at: http://www.nutritionsociety.org 